\title{
An analysis of the mirror-induced objective self-awareness effect
}

\author{
PAUL B. PAULUS, ANGELA B. ANNIS, and HAL T. RISNER \\ University of Texas, Arlington, Texas 76012
}

\begin{abstract}
The present study assessed the combined effect of mirror presence and degree of evaluation apprehension on task performance and palmar sweating. The primary finding of interest was that mirror presence led to a reduction in palmar sweating but no such reduction occurred in a condition in which no mirror was present. Since other studies have shown that audience presence increases palmar sweating, the results of the present experiment suggest that, contrary to objective self-awareness theory, mirror presence and audience presence may involve different psychological processes.
\end{abstract}

A strong interest has been evidenced in the effects of spectators and co-workers (co-actors) on an individual's task performance (cf. Geen \& Gange, 1977). The results in this area of research have been given a theoretical structure by Zajonc (1965). Noting that other presence generally facilitated performance on simple and welllearned tasks, Zajonc suggested organizing the data in this area using Hull-Spence theory. He argued that other presence is a source of drive arousal and hence facilitates dominant responses. On well-learned or simple tasks, the correct responses are supposedly dominant and task facilitation should occur due to drive arousal. On poorly learned or complex tasks, the incorrect responses are supposedly dominant, and hence task interference should occur as a result of drive arousal. Zajonc (1965) argued that the arousing effect of other presence is simply an innate response to the mere stimulation of the other individual's presence. Others (Cottrell, 1972; Henchy \& Glass, 1968; Paulus \& Murdoch, 1971) have argued that other presence has its effect because it induces a concern about the potential evaluative outcomes. This position has received considerable support (cf. Geen \& Gange, 1977).

Duval and Wicklund (1972) have proposed yet another interpretation which does not include the drive arousal concept. They proposed that other presence induces a state of objective self-awareness. That is, the presence of others supposedly makes an individual more aware of himself as an object to be evaluated and makes the individual more concerned about the extent to which his performance meets certain standards of correctness. Duval and Wicklund argue that this increase in objective self-awareness leads one to try to meet the presumed standards of correct performance, leading to

This research was supported in part by funds from the Organized Research Committee of the University of Texas at Arlington. The able assistance of Jeanne Schemmerhorn in this research is gratefully acknowledged. Requests for reprints should be sent to Paul B. Paulus, the University of Texas at Arlington, Arlington, Texas 76012. subsequent facilitation of task performance. The occurrence of decrements in performance in spite of the increased "trying" is attributed simply to trying beyond one's capabilities. Wicklund and Duval (1971) argued that even one's image in a mirror should produce a state of objective self-awareness. Consequently, the presence of a mirror should facilitate performance on simple tasks. Choosing a task in which subjects were asked to copy German prose, they indeed found that the presence of the mirror increased the number of words copied. Liebling and Shaver (1973) subsequently replicated this finding and also tried to demonstrate that, under very highly evaluative conditions, the mirror might lead to decreased performance since too much attention to self should interfere with task performance. Their results tend to support this prediction.

The present study was designed to assess whether or not mirror presence produces a change in drive arousal. Duval and Wicklund (1972) assume that no such arousal occurs. However, if such arousal does occur, it could be argued that the Wicklund and Duval results can be incorporated into Zajonc's social facilitation theory. A palmar sweat measure used in a number of social facilitation studies (Cohen \& Davis, 1973; Martens, 1969) provides one means of measuring drive arousal. Changes in palmar sweat (either increases or decreases) are presumed to reflect increased arousal. Audience presence generally leads to increases in palmar sweating. On the basis of Duval and Wicklund's presumption that the psychological effects of audience presence and mirror presence are similar, one might expect that mirror presence also would lead to an increase in palmar sweating. The present study consisted of a replication of the experimental design employed by Liebling and Shaver (1973), with the addition of the palmar sweat measure.

\section{METHOD}

Forty females and 15 males from introductory psychology classes participated to fulfill a class requirement. All subjects were initially asked to copy passages of German prose for $5 \mathrm{~min}$. 
One half of the subjects were instructed that the task was a test of their ability and intelligence, as in the Liebling and Shaver (1973) high-evaluation condition. The other half were given the same instructions as those in the Wicklund and Duval (1971) study and the Liebling and Shaver low-evaluation condition. Within each of the two evaluation conditions, for one half of the subjects a mirror was turned over to face them while they wrote for a second 5-min period. The other subjects continued for a second 5-min period without a mirror facing them. Palmar sweat measures were taken when the subject first arrived for the experiment, after finishing the first session, just prior to the second session, after the mirror was turned over (and at the comparable time in the no-mirror conditions), and after the second session. Other than the palmar sweat measure, the instructions, procedures, and task setting were an exact replication of Liebling and Shaver's (1973) study. The palmar sweat technique is described in detail by Dabbs, Johnson, and Leventhal (1968).

\section{RESULTS}

The first dependent variable analyzed was the mean increase in letters copied from Session 1 to Session 2. The data from three subjects were randomly deleted to allow the use of equal Ns for the analysis of variance. This data is summarized in Table 1 and was subjected to a 2 by 2 between-subjects analysis of variance, with evaluation level and mirror presence as factors. This analysis revealed a significant Evaluation by Mirror Presence interaction $\cdot[\mathrm{F}(1,48)=4.63, \mathrm{p}<.05]$. As shown in Table 1, the nature of this interaction is opposite to that obtained by Liebling and Shaver (1973), with mirror presence increasing the amount of prose copied in the high-evaluation condition but having the reverse effect in the low-evaluation condition.

The last three palmar sweat measures were subjected to a 2 by 2 by 3 repeated-measures analysis of variance. It was felt that the third measure would be most appropriate as a baseline measure for later changes due to mirror presence. Palmar sweat data were not available from three subjects. The data from one additional subject was randomly deleted to produce equal Ns in all conditions. The palmar sweat count on the last three trials is shown in Table 2 . The analysis of variance revealed a significant main effect of trials $[F(2,132)=44.4$, $\mathrm{p}<.025]$, a Mirror Presence by Trials interaction $[\mathrm{F}(2,132)=4.07, \mathrm{p}<.025]$, and an Evaluation Type by Trials interaction $[F(2,132)=3.75, p<.05]$. As shown in Table 2, the interaction of mirror presence and trials was due to reduction in palmar sweat scores during mirror presence (Trials 4 and 5 in the mirror conditions). The interaction of evaluation and trials resulted from increased palmar sweat scores on Trial 5 for the subjects in the high-evaluation conditions.

\section{DISCUSSION}

The palmar sweat results indicate that, in both mirror conditions, palmar sweating was decreased after the mirror was turned over. No such decrement was observed in the no-mirror condition. This result is contrary to the finding that audience presence
Table 1

Mean Change in Number of Words Copied

\begin{tabular}{lcc}
\hline & Mirror & No Mirror \\
\hline Low Evaluation & 13.15 & 84.00 \\
High Evaluation & 36.85 & 18.23 \\
\hline
\end{tabular}

Table 2

Mean Palmar Sweat Scores

\begin{tabular}{cccccc}
\hline & \multicolumn{2}{c}{ Mirror } & & \multicolumn{2}{c}{ No Mirror } \\
\cline { 2 - 3 } \cline { 5 - 6 } Trials & \multicolumn{2}{c}{ Evaluation } & & \multicolumn{2}{c}{ Evaluation } \\
& High & Low & & High & Low \\
\hline 3 & 28.21 & 21.58 & & 23.83 & 21.58 \\
4 & 16.00 & 11.62 & & 23.42 & 22.62 \\
5 & 25.92 & 12.75 & & 38.58 & 23.75 \\
\hline
\end{tabular}

increases palmar sweating and suggests that potentially different psychological processes may underlie the effects of audience presence and mirror presence. For example, Dabbs et al. (1968) suggest that increased palmar sweating may indicate increased vigilance to a stressful environment, whereas a decrease in palmar sweating may indicate a decreased attention to a stressful environment and increased attention to self. Although this notion is quite speculative, it suggests the possibility that stress produced by audience presence is accompanied by increased attention to the audience members. In contrast, the mirror-produced stress may be accompanied by decreased attention to the mirror and more to the self, as with objective self-awareness. The finding of the present study that mirror presence and audience presence may have different psychological effects is consistent with the finding of a recent study by Innes and Young (1975). They found that audience presence led to a reduction in performance on a mirror-tracing task under both low- and highevaluation conditions; mirror presence had no effect under lowevaluation conditions but led to enhanced performance under high-evaluation conditions.

The fact that mirror presence produced a change in arousal is, of course, counter to the assumption by Wicklund and Duval (1971) that mirror presence effects are not mediated by changes in arousal. Furthermore, the finding of an arousal effect of mirror presence suggests that the mirror effect could be subsumed in Zajonc's (1965) social facilitation theory. The increased palmar sweating that was evident on the last measure in the two high-evaluation conditions may indicate increased concern of the subjects over the impending evaluation of their justfinished performance. This increase in palmar sweating may be similar to that obtained in the presence of an evaluative audience.

The effect of mirror presence on prose copying in the present study was, of course, opposite to that found by Liebling and Shaver (1973). Yet the results of the Innes and Young (1975) study are similarly inconsistent with the Liebling and Shaver study in that they also found enhancement of performance due to mirror presence in the high-evaluation condition and no effect in the low-evaluation condition. The explanation for the inconsistencies among the various studies may lie in an inverted$\mathrm{U}$ relationship between performance and degree of evaluation. The results of both the Innes and Young and Liebling and Shaver studies are consistent with such a proposal (cf. Innes \& Young, 1975). That is, in both of these studies, as the number of evaluative cues increases (i.e., evaluative instructions, mirror presence, and audience presence), task performance appears at first to be facilitated, but at some point increased evaluation produces a decrement in performance. In the present study it could be argued that the use of the palmar sweat procedure increased the overall degree of concern for task evaluation in 
both the low- and high-evaluation conditions. Thus, in contrast to the conditions of the Liebling and Shaver study, the conditions in the present study might actually have been high evaluation and very high evaluation. Hence, the low-evaluation/nomirror condition in the present study may have produced an optimum level of evaluation apprehension, but the level of apprehension in the low-evaluation/mirror and the two highevaluation conditions may have been too high for optimal performance. The results of the present and previous studies thus suggest that whether or not mirror presence enhances task performance does indeed depend on the overall level of evaluation apprehension, but exact predictions will be difficult to make unless one can a priori specify the degree to which the level of apprehansion induced by a particular condition is either suboptimal, optimal, or superoptimal. Recent research on the effects of mirror presence on aggression supports this contention (Carver, 1974; Scheier, Fenigstein, \& Buss, 1974).

\section{REFERENCES}

CARver, C. S. Facilitation of physical aggression through objective self-awareness. Journal of Experimental Social Psychology, 1974, 10, 365-370.

Cohen, J. L., \& Davis, J. H. Effects of audience status, evaluation and time of action on performance with hiddenword problems. Journal of Personality and Social Psychology, 1973, 27, 74-85.

CotTrell, N. B. Social facilitation. In C. B. McClintock (Ed.), Experimental social psychology. New York: Holt, Rinehart, \& Winston, 1972.

Dabbs, J. M., JR., Johnson, J. E., \& Leventhal, H. Palmar sweating: A quick and simple measure. Journal of Experimental Psychology, 1968, 78, 347-350.
Duval, S., \& Wicklund, R. A. A theory of objective selfawareness. New York: Academic Press, 1972.

GeEN, R. G., \& GANGE, J. J. Drive theory of social facilitation: Twelve years of theory and research. Psychological Bulletin, 1977, 84, 1267-1288.

Henchy, T., \& Glass, D. D. Evaluation apprehension and the social facilitation of dominant and subordinate responses. Journal of Personality and Social Psychology, 1968, 10, 446-454.

InNEs, J. M., \& Young, R. F. The effect of presence of an audience, evaluation apprehension and objective selfawareness on learning. Journal of Experimental Social Psychology, 1975, 11, 35-42.

Liebling, B. A., \& Shaver, P. Evaluation, self-awareness, and task performance. Journal of Experimental Social Psychology, 1973, 9, 297-306.

Martens, R. Palmar sweating and the presence of an audience. Journal of Experimental Social Psychology, 1969, 5, 371-374.

Paulus, P. B., \& Murdoch, P. Anticipated evaluation and audience presence in the enhancement of dominant responses. Journal of Experimental Social Psychology, 1971, 1, 280-291.

Scheier, M. F., Fenigstein, A., \& Buss, A. H. Selfawareness and physical aggression. Journal of Experimental Social Psychology, 1974, 10, 264-271.

Wicklund, R. A., \& Duval, S. Opinion change and performance facilitation as a result of objective selfawareness. Journal of Experimental Social Psychology, 1971, 7, 319-342.

ZAJONC, R. B. Social facilitation. Science, 1965, 149, 269-274.

(Received for publication March 1, 1978.) 